\title{
Obstetric Fistula in the Developing World: An Agonising Tragedy
}

\author{
Dangal G, ${ }^{1}$ Thapa $K,{ }^{2}$ Yangzom $K,{ }^{3}$ Karki $A^{1}$ \\ ${ }^{1}$ Department of Obstetrics and Gynaecology, Kathmandu Model Hospital, Kathmandu, \\ ${ }^{2}$ Jhpiego, Lalitpur, Nepal \\ ${ }^{3}$ Department of Obstetrics and Gynaecology, Patan Academy of Health Sciences, Lalitpur.
}

\begin{abstract}
Obstetric fistulae is the most tragic of preventable childbirth complications in the developing world, as affected women are often abandoned by their husbands and family, and forced to live in shame. They occur almost entirely in the developing world and their incidence is poorly studied. Their management requires accurate diagnosis, sufficient pre-operative workup, fine surgery following standard surgical repair steps and principles by skilled surgeons, specialised post-op care, and follow-up. As obstetric fistula is a serious preventable public health issue in developing countries, national and international organizations should launch a campaign to end fistula by increasing the resources and skilled staff available locally to treat obstetric fistula for improving the lives of women currently living with this condition. Moreover, effective preventive strategies for obstetric fistula such as better education to women and provision of improved obstetric care and searching for the best approaches to both prevention and treatment should be the priority. The materials published in PubMed, Lancet, Medline, WHO and Google Scholar web pages from 1990 to 2013 have been utilized to prepare this paper.
\end{abstract}

Keywords: fistula prevention, fistula repair, Nepal, obstetric fistula, obstructed labor.

\section{INTRODUCTION}

Obstetric fistula is an abnormal opening between the reproductive tract and the urinary tract or alimentary tract or both. Obstetric fistula typically develops after several days of prolonged or obstructed labour. The genitourinary or rectovaginal fistula occurring after labor and its complications are labeled as obstetric fistula $(\mathrm{OF}) .^{1-4}$

Obstetric fistula remains a major public health problem in developing world where unattended obstructed labor is common and maternal mortality is unacceptably high. It is a tragedy of developing world because of illiteracy, poverty, ignorance and lack of health facilities. Obstetric fistulas can be completely prevented by the provision of proper health care. Obstructed labor fistula or obstetric fistula occurs almost exclusively in developing countries where access to intra-partum clinical care

\section{CORRESPONDENCE}

\section{Dr Ganesh Dangal}

Department of Obstetrics and Gynaecology,

Kathmandu Model Hospital, Exhibition Road,

Kathmandu, Nepal.

Email: ganesh.dangal@gmail.com

Phone: +977-9851055036 is far from the hyper-vigilant standards employed for women living in wealthy nations. In developed nations, genital fistulae occur most commonly as a result of gynecologic surgery, and less commonly by infections, radiation injury, sexual violence or obstetrical trauma.

The evaluation and treatment of obstetric fistula creates one of the most challenging clinical scenarios in soft-tissue reconstructive surgery. The preparation for surgery, surgical technique, and post-operation wound healing each bear significant impact on the final outcome. The first operation presents the best opportunity for successful outcome. Fistula recurring after attempted surgical repair is often bigger, more fibrotic, or more complex. Optimal fistula programming is predicated on the principle that all fistula warrant hyper-vigilant attention to the details of patient preparation, meticulous reconstructive surgical technique, and rigorous post-operative care paradigms. ${ }^{1,2}$

The papers in this journal are published under the terms of the Creative Commons Attribution License. Users are allowed to read, download, copy, distribute, print, search, or link to the full texts of the articles in this journal without asking prior permission from the publisher or the author. 


\section{METHODS}

We did a literature review for assessing the $\mathrm{OF}$ publications. The literature search focused mainly on the findings of the studies that were published in national and international levels. The method adopted for review was literature search from PubMed, Medline, Lancet, WHO and Google Scholar web pages published from 1990 to 2013. Different search terms like obstetric fistulae, vesico-vaginal fistulae, recto-vaginal fistulae, childbirth injury, urinary incontinence, and classification of fistulae were used to locate relevant references and the location of the relevant journal articles. This was augmented by unpublished literature and relevant experience sharing obtained by contacting experts in the field. We also looked at other relevant publications like reports, training manuals and books.

\section{Magnitude of fistula}

The true prevalence of obstetric fistula $(\mathrm{OF})$ is not fully documented. In 2006, WHO estimated and quoted that "2 million women worldwide" were affected with fistula. However, the method or data used to validate this widely quoted global number has never been disclosed. ${ }^{4}$ Literature on OF suggest empiric estimates or facility-based prevalence of OF admissions as a proportion of gynecologic admissions that at best reflect regional trends, and the sheer persistence of this preventable complication of pregnancy. The prevalence data for OF in Southeast Asia is, as in many parts of the world, suboptimal. In 2006, UNFPA's survey on Status of Reproductive Morbidities in Nepal showed that three women out of 2070 women evaluated had OF. This data yielded an extrapolated population rate of $0.15 \%{ }^{5}$ Thousands of women in Nepal suffer silently from vesicovaginal fistula. It is estimated that $200-400$ new cases of obstetric fistula occur each year in Nepal. In a country with intermediate incidence (until 0.6/1000), it is estimated that 56.4 fistulas per 100,000 women aged 15- 49 suffer from this condition. Thus, there are 4362 OF prevalent cases in Nepal. ${ }^{6} \mathrm{OF}$ is known to occur in the rural and remote regions of Nepal. Lack of accurate prevalence for OF continues to challenge the medical community for providing care for these women. $^{7}$

\section{Pathophysiology of fistula}

In developing countries, obstructed labor is one of the top five causes of maternal mortality. Ninty-nine percent of all maternal deaths occur in developing countries. In developed countries, obstructed labor is not permitted to progress beyond a few hours, and is no longer a source of maternal mortality. On the other hand, maternal mortality remains unacceptably high in developing countries. In developing countries, obstructed labor, hemorrhage, infection, hypertension, and unsafe abortion remains the top five reasons of pregnancy related deaths. ${ }^{8}$ Even among women who do not die from obstructed labor, many still suffer from the dual devastation of a stillborn infant and obstetric fistula. The fetal head impacted against the bony pelvis crushes the vaginal soft tissue during the days of unattended obstruction. This causes ischemia and results in soft tissue necrosis. This ischemic necrosis leads toformation of fistula and abnormal adhesions between the uterus and/or vagina. The adjacent urinary and colorectal organs are also affected by the ischemia. These defects bypass the normal storage of anatomic functions of the urinary and colorectal tracts. These lead to profound and continuous incontinent flow of urine and/or feces. ${ }^{3}$

\section{Etiology of fistula \\ Obstetric causes}

1. Prolonged obstructed labor is the predominant cause of obstetric fistulae.

2. Other causes include: destructive delivery, instrumental deliver, cesarean delivery with or without hysterectomy, traditional practices, etc.

\section{Non-obstetric causes}

1. Traumatic like coitus, sexual violence, accidental trauma and female genital mutilation

2. Infection such as granulomatous infection, tuberculosis and HIV infection

3. Congenital (rare)

4. Malignancy (especially cervical cancer) and /or radiotherapy

5. Iatrogenic (during pelvic surgery)

The major cause of obstetric fistula is obstructed labor without Emergency Obstetric Care (EmOC) interventions - oxytocin augmentation of labor, instrumental assisted vaginal delivery, and cesarean section being the mainstay therapies. The condition may be labeled "failure to progress" or "cephalopelvic disproportion" when managed appropriately on time and "obstructed labor" when management is delayed. The time taken to intervene at different stages of obstruction can lead to vastly different outcomes. Obstructed labor almost always is associated with fetal asphyxia and stillbirth. Many mothers may also suffer from lumbosacral compression neuropraxia that results in foot drop. Furthermore, extensive vaginal fibrosis results in a stone-hard consistency of vaginal walls. Obstetric fistula may also occur without obstructed labor, such as in the case of rectovaginal fistula, it can occurr due to breakdown of episiotomy 
or vaginal tear repair suture lines, or due to cesarean section complications. When a fistula occurs after cesarean section following labor that lasts less than a day, it is usually safely assumed to be due to errors of technique. However, it is challenging to assume poor surgical technique as a cause of fistula when cesarean section is performed for classic obstructed labor. In these circumstances, particularly in uterine rupture, the surgery is performed through tissue planes with compromised blood flow and endometritis, with secondary severe distortion of intra-abdominal pelvic anatomic landmarks. ${ }^{9}$ The cause of any subsequent fistula in these circumstances may be due to exacerbation of the edema/ischemia/necrosis cascade due to the introduction of an incision and suture line into the proximal aspects of the damaged organ systems. The fistulae in these cases could be more complex than it may have otherwise.

Female genital tract fistula also occur after pelvic surgery, most commonly following hysterectomy. Abdominal surgery has higher risk than vaginal hysterectomy, and an almost zero incidence with supracervical hysterectomy. In wealthy nations, gynecologic surgery is the most common cause of genital tract fistula, with a common "risk of fistula" rate quoted at $2 \%$ for benign hysterectomy surgical risk. Fistula may also occur after genital trauma, most often following foreign-body rape which is considered as a gender violence tool of warfare in some war-torn areas. ${ }^{10}$ Uterovaginal prolapse is rarely associated with genitourinary fistula. When it occurs, it usually involves an untended pessary-related erosion through the vaginal wall into the bladder or bowel, or fistulous erosion of uterovaginal prolapse. ${ }^{11}$

\section{Diagnosis, classification, prognostic factors and outcomes \\ Overview of client assessment}

Careful evaluation of all potential involved anatomy is crucial as there may be more than one fistula. A renal sonogram or intravenous urography is best used liberally whenever available, to identify hydronephrosis/hydroureter and end-stage renal atrophy. Blood urea nitrogen and creatinine values provide a gross indication of overall renal function. With hydronephrosis, ureteric re-implantation is necessary. With end-stage renal atrophy, the ipsilateral ureter may not efflux, and knowing that the kidney is non-functional saves much time and effort during the operation. Pelvic neuropraxia of the sacral nerve roots, caused by the same fetal impaction cascade, may result in saddle anesthesia with dermal ulcerations due to incontinence combined with the inability to sense pain, infection and necrosis in the numbed soft tissues of the affected dermatomes. ${ }^{1}$ The peroneal nerve, which controls foot flexion and eversion, is particularly vulnerable to obstetric compression of the lumbosacral plexus. If left untreated, permanent inversion/plantar flexion with atrophy of extensor and peroneous muscles and contraction of the Achilles tendon may result, requiring surgical intervention ${ }^{12}$ Walking as early as possible, with cane or crutches is highly advised as a prevention to full blown peroneal neuropraxia. ${ }^{1}$

Many women with fistula also have stones along the fistula tract. This is mainly due to dehydration as a result of reduced intake of water either due to lack of access to potable water or intentionally not taking enough water in order to reduce and control the volume for incontinence of both urine and stool. In addition, the fistula patients use intra-vaginal cloth, vegetation or other "sponge" material frequently, that may precipitate stones. Damage to the urethra may render the patient chronically incontinent even if the "hole is closed", in a drainpipe-urethra stress incontinence condition. ${ }^{1}$ Damage to the parasympathetic plexus may cause overactive bladder to be considered in the closed-but-incontinent fistula patient. Fistula patients expect that all pelvic functions will be normal after their fistula surgery. It is important to counsel such patients for the possibility of infertility and vaginal scarring precluding normal coitus that will not be restored by fistula surgery. Many women with fistula are not sexually active until the fistula is fixed. If a repaired fistula patient sustains the unfortunate coital limitations caused by distorted, shortened and strictured vagina by dense fibrosis, proper patient counseling helps to prepare herself for marital intimacy in a realistic fashion.

Rectovaginal fistulae are less common than vesicovaginal, as the rectal vault is not so entrapped by the bony pelvis during obstructed labor. It is quite common for a rectovaginal fistula to accompany the more common vesicovaginal fistula when obstructed labor is the cause. Rectovaginal fistula may also occur as a complication of episiotomy or spontaneous perineal tears sustained during normal, non-obstructed labor, and without any concomitant vesicovaginal fistula. When a combination of urinaryrecto-genital fistula occurs, wound healing dictates the repair of the rectovaginal fistula. With a staged approach, repair of the vesicovaginal fistula can be done once the rectovaginal fistula is fully closed and well healed.

Obstetric fistula patients may have spontaneous symphyseal separation requiring binding, activity restriction and physical therapy. Osteitis pubis 
must be considered in the differential diagnosis list of obstructed labor. Some women suffer from ulcerations of the buttocks and ischial tuberosities due to neuropraxic saddle anesthesia, or severe urine dermatitis from constant incontinence. ${ }^{1}$ In such cases, pre-operative care includes active skin and wound care to reduce the cellulitis and heal open granulation beds before undergoing fistula repair surgery. The near- $100 \%$ rate of stillbirth, the $30-60 \%$ rate of marital abandonment, and extreme social isolation induces a reactive depression that may warrant ongoing care even after successful surgery, as the post-traumaticstress disorder features may be severe.

\section{History and clinical examination}

\section{History taking}

A general history and physical screening allows the clinician to assess general health factors that will help to prepare the woman for surgery. Most fistula patients are not the type to go for check-ups and health screenings. A focused uro-gynecologic and colorectal history is obtained, with focused examination to delineate not only the fistula, but precedent conditions that may affect uro-gynecologic/colorectal function after successful closure of the fistula. A patient with daily leakage of urine with heavy lifting, or fecal incontinence to solid stool prior to the delivery that caused the fistula may be expected to continue to have those symptoms even after a fistula is closed. With regards to the fistula, the client may have leaking urine, stool, or both. The duration of fistula symptoms and years since fistula-related event are noted. Neonatal status of last delivery and whether the fistula event was obstetric, gynecologic, or other is recorded. If she wore a catheter for the fistula, obtain the details. Specifics of the clinical events related to the fistula are obtained - vaginal birth or cesarean? Any other relevant information is obtained.

\section{Clinical examination}

Examination, while focused on the fistula defect, nevertheless warrants a thorough head-to-toe, documented examination. Physical screening for nutritional, thyroid, cardiopulmonary, abdominal, retroperitoneal, neurologic, orthopedic and dermatologic pathology allows optimal woundhealing preparation for the extensive soft-tissue reconstructive surgery required for many OF. Unlike extirpative surgery involving the removal of organs, the success of any reconstructive surgery including the one for fistula depends greatly on optimal wound healing. A woman with advanced thyroid disease, uncontrolled diabetes, extreme nutritional deprivation, or uncontrolled hypertension will not heal well, and when found on fistula screening evaluation, every effort must be made to correct and balance physiologic functions prior to surgery. Evaluation of fistula includes written description (size, location from anatomic staging landmark, fibrosis, other confounding factors), staging, blue test (genitourinary), and drawing of the $\operatorname{defect}(\mathrm{s})$. A rectovaginal version of blue testing may be done by inserting blue exam gel into the rectum, $\sim 15 \mathrm{ml}$. Compress the gel against the anterior rectal wall with an examining finger while exposing the posterior vaginal wall with a retractor and bright lighting. Blue gel may express through small RVF in this fashion.

Examination is performed for gross nutritional status, developmental stage and mental status. Review of respiratory, cardiovascular, abdominal, musculoskeletal and neurologic systems is done. Neurologic system is affected by symptoms (such as foot drop or saddle anesthesia) caused by obstructed labor. If anal reflex and pudendal nerve function are impaired, residual stool and or flatal incontinence may continue to trouble the patient despite good anatomic repair. The external genitalia are examined for signs of ulceration and excoriation ('urine dermatitis') and bleeding, stone, genital mutilation, perineal tears, etc. Speculum and digital examination allows us to diagnose fistula and to take note of any characteristics that may affect treatment and outcome.

\section{Genitourinary dye test}

A dye test detects a small or unusual fistula, especially a utero-vaginal or cervico-vaginal fistula. It may be carried out on screening evaluations, or during examination under anesthesia. A dye test is performed by inserting dry cotton swabs into the vagina and instilling methylene blue or other sterile colored solution into the bladder by means of a catheter. The swabs are removed after a few minutes. If the swab that was the lowest in the vagina is stained, the patient has a urethro-vaginal fistula; if the middle swab is stained, the patient has a vesico-vaginal fistula; and if the upper swab is stained, the patient has a juxtacervical fistula, a vault fistula, a uretero-vesical fistula or a cervico-vesical fistula. If the upper swab is stained with urine but not with dye, the patient has a uretero-vaginal fistula.

\section{Pre-operative investigations}

Some of the following investigations will not be available and probably not essential at all centers:

1. Hematocrit, blood group and Rh group

2. Additional tests:
a. Blood tests for HIV infection, syphilis, hepatitis and renal function
b. Urinalysis and urine culture: Almost all 
genitourinary and many intestine-urinary fistulae women have colonized urinary tracts. Unless frankly purulent or findings consistent with active upper tract infection, pre-op urinalysis and/or urine culture to direct antibiotic therapy for cystitis is not proved to be helpful or necessary.

c. Stool tests for occult blood, ova and parasites

d. Ultrasound exploration of kidney, ureter and bladder. Look for stones and obstruction, especially if the patient previously had a fistula repair or an abdominal operation (especially, a cesarean delivery or a hysterectomy).

e. Radiologic exploration: Intravenous urography to look for stones and obstruction and assess renal function

f. The indigo carmine test to look for ureteric fistulae

g. Endoscopy: Cystoscopy and urethroscopy

h. ECG and Chest X-ray when indicated

i. Barium enema: Colorectal pathology, nonpalpable fistulous tracts

\section{Classification and staging}

A classification system should be descriptive, indicative as well as prognostic (i.e. present a description, indicate the operative technique to be applied and the outcome to expect) and it should be a reliable tool for study and communication. Each fistula is unique, and there are so many variables that some surgeons feel that a satisfactory classification will never be achieved. One system cannot be recommended over another until there is an accepted standardized classification system.

\section{Current classification systems}

1. The Waaldijk System $^{13}$ is based on whether the continence mechanism is impaired and on circumferential damage. Studies have been conducted to assess this system, which is presently used in West and East Africa.

2. The Goh System ${ }^{14}$ is based on urethral involvement, size of defect, extent of scarring, whether scarring is circumferential, and whether repair has previously been attempted. Studies have been conducted to assess this system, which is presently used at several centers in East Africa.

3. The Francophone System has been partially validated and is used in francophone Africa.

4. The two-stage Tafesse System ${ }^{15}$ is based on urethral involvement, extent of scarring, whether the continence mechanism is affected, and bladder capacity. This system has not been assessed and is not validated.

\section{Outcome and prognosis}

The critical factors affecting the prognosis of an obstetric fistula are the length of the urethra, the sizes of the fistula and the bladder, and the amount of scarring. Almost all defects can be closed. However, if the urethra has been crushed, denervated and shortened, it will not function and the patient may have total stress incontinence. The shorter the urethra and the greater the scarring, the higher is the chance of stress incontinence. Destroyed urethras can be repaired, but the prognosis for continence is not good. Incontinence persisting after repair can be predicted by the following by urethral involvement, important scarring, and size of defect and bladder capacity. The main classifications are based on the degree of involvement, or not, of the closing mechanism since this will have consequences for the operative technique and the prognosis of the repair.

\section{Grading of the degree of anticipated difficulty of the repair ${ }^{4}$}

This classifies fistula into two groups according to the degree of operative difficulty:

- Good prognosis/simple fistula able to be repaired by surgeons fully trained and competent to undertake uncomplicated fistula repairs.

- Uncertain prognosis/complicated fistula that will require referral to, and repair by, a specialist fistula surgeon.

Table 1. Criteria based on the degree of anticipated difficulty of the repair.

\begin{tabular}{|c|c|c|}
\hline Defining criteria & $\begin{array}{l}\text { Good prognosis/ } \\
\text { Simple }\end{array}$ & $\begin{array}{l}\text { Complicated/ } \\
\text { Uncertain }\end{array}$ \\
\hline Number of fistula & Single & Multiple \\
\hline Site & vesico-vaginal (VVF) & $\begin{array}{l}\text { RVF, mixed VVF/ } \\
\text { RVF, involvement of } \\
\text { cervix }\end{array}$ \\
\hline Size (diameter) & $<4 \mathrm{~cm}$ & $>4 \mathrm{~cm}$ \\
\hline $\begin{array}{l}\text { Involvement of the } \\
\text { urethra/continence } \\
\text { mechanism }\end{array}$ & absent & Present \\
\hline $\begin{array}{l}\text { Scarring of vaginal } \\
\text { tissue }\end{array}$ & absent & Present \\
\hline $\begin{array}{l}\text { Presence of } \\
\text { circumferential } \\
\text { defect* }\end{array}$ & absent & Present \\
\hline Degree of tissue loss & minimal & Extensive \\
\hline $\begin{array}{l}\text { Degree of tissue } \\
\text { loss Ureter/bladder } \\
\text { involvement }\end{array}$ & $\begin{array}{l}\text { ureters are inside the } \\
\text { bladder, not draining } \\
\text { into the vagina }\end{array}$ & $\begin{array}{l}\text { ureters are draining } \\
\text { into the vagina, } \\
\text { bladder may have } \\
\text { stones }\end{array}$ \\
\hline $\begin{array}{l}\text { Number of attempts } \\
\text { at repair }\end{array}$ & no previous attempt & $\begin{array}{l}\text { failed previous } \\
\text { attempts of repair }\end{array}$ \\
\hline
\end{tabular}

* the complete separation of the urethra from the bladder 


\section{Prevention of obstetric fistula}

Every year, many tragic cases of fistula occur among women from underserved communities. Many women in remote villages go through labor either alone or with the help of family or a local, untrained birth attendant, far away from professional health care. Furthermore, they lack accessible means of transport when complications following labor arise. It is an unfortunate fact of humanity that life-threatening obstructed labor occurs with great frequency when women leave it "up to nature". Evidence shows that modern obstetric care can prevent the five most common causes of maternal mortality still ravaging the developing world, obstructed labor being one of them.

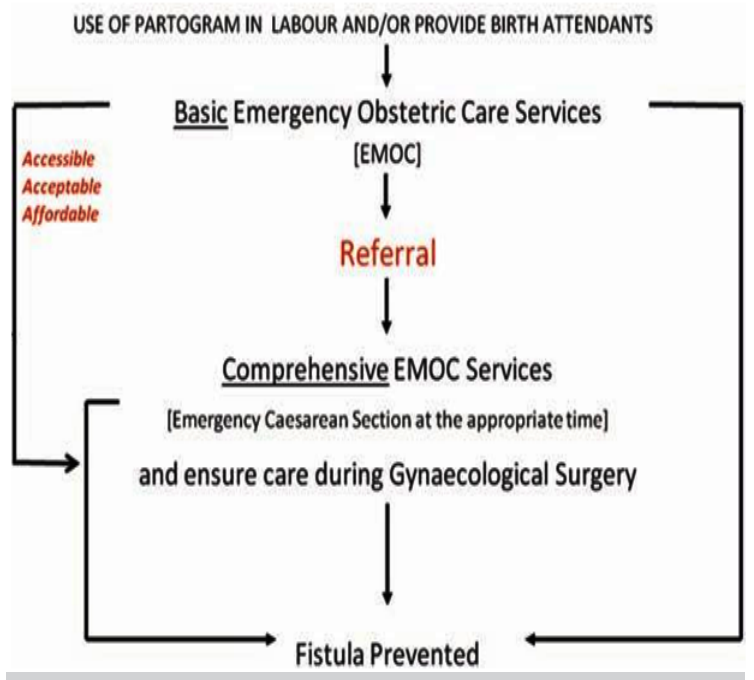

Figure 1. Algorithm to help prevent fistulae.

Source: Global Competency-based Fistula Surgery Training Manual. FIGO and Partners. London: FIGO;2011. ${ }^{16}$

\section{Lack of access to maternity care ${ }^{4}$}

In poor countries, majority of the women who die, or who develop fistula during childbirth, do so because they did not receive the health care that they needed. This may be due to a lack of basic health-care provision or through an inability to access the local health-care services.

\section{Strategies for prevention of $\mathbf{O F}$}

The need for OF prevention and treatment services will vary greatly between individual countries or areas.

The goal of any fistula program for delivering preventive and treatment services should:

- Prevent women from developing fistula through health promotion and awareness, and the development of high-quality basic and comprehensive maternal health services, available to all.
- Ensure that all women living with fistula have easy and early access to skilled professionals who are able to repair simple fistula and/or refer more complex cases to higher center.

\section{Recommendations to prevent $\mathrm{OF}$ fall into three types $^{4}$ \\ Primary-prevention strategies}

These are aimed at ensuring that pregnancies are planned, wanted, and occur at an optimal age. These strategies ensure that all women, their families and communities, understand the need for delaying the age of first pregnancy, as well as the advantages of birth spacing and providing access to family planning. In developing world, girls and women receive less nutritious food. They have underdeveloped pelvises that often increase the incidence of obstructed labor. Girls are also less likely to be educated. The wider social determinants for the improvement of the general health of girls and women may include, for example, addressing issues such as better child and adolescent nutrition, recognizing a girl's right to education and setting a minimum age for marriage.

\section{Secondary-prevention strategies}

When a woman is pregnant, the woman herself, her family and the community need to be aware of the need to seek antenatal care and the importance of skilled care at childbirth. This can be promoted by increasing community awareness, training traditional birth attendants, increasing women's knowledge of normal pregnancy and delivery, and about when and where to seek help, and why. However easy access to a local essential obstetriccare facility is paramount. ${ }^{17}$ They should have access to comprehensive obstetric-care services. ${ }^{18}$ Consistent use of a partograph for the correct monitoring of labor has been proven effective for the early diagnosis and management of prolonged/obstructed labor. A referral to a setting in which a caesarean section or assisted vaginal delivery can be performed in a timely manner is the key intervention to prevent deaths and complications related to obstructed labor.

\section{Tertiary-prevention strategies}

These are designed to identify and prevent the development of fistula in labor or in recently delivered women who are at risk. This includes monitoring every labor by use of a partograph. Midwives and doctors should also be trained to help prevent fistula formation or to enable closure of very small fistula without surgery by the use of an indwelling urinary catheter for mothers who have survived an obstructed labor. 


\section{Management of obstetric fistula}

The evaluation and treatment of obstetric fistula create one of the most challenging clinical scenarios in soft-tissue reconstructive surgery. Management of obstetric fistula can be divided into conservative and surgical treatment.

\section{Conservative management of fistula}

\section{Catheter and debridement immediately postpartum after obstructed labor}

Immediate catheter drainage of the bladder prevents fistula formation in a site of vaginal wall necrosis when inserted immediately after obstructed-labor delivery. Fifteen to $20 \%$ of fresh obstetric fistula may achieve spontaneous closure by catheter drainage when inserted immediately after obstructed labor delivery. ${ }^{1}$ Excision or other debridement method of fibrinous exudate, purulence and devitalized tissues, followed by thorough irrigation with saline should be done. After a caesarean section for prolonged obstructed labor, the catheter should be retained for at least 10 days. If there is urinary leakage after removal of the catheter, it should be reinserted immediately.

\section{Early fistula closure through catheter drainage or surgery}

Fistulae may be successfully closed surgically at any point provided the tissue quality is optimized (no infection or crusting, minimal induration). ${ }^{19,20}$ Continuous bladder drainage by catheter should be maintained for a minimum of four to a maximum of six weeks. Many experienced fistula surgeons prefer to operate as soon as the vagina is clear of necrotic tissues. While others prefer to wait for two to three months after the fistula has occurred.

\section{Alternative fistula procedures: plugs, cautery and glue \\ Endoanal fistula plugs, made of Surgisis-brand porcine of small intestine sub-mucosa facilitate in spontaneous closure of small rectovaginal fistula by creating a growth-factor laden matrix that mechanically closes the hole while catalyzing histologic aspects of wound heaing. ${ }^{21}$ This may be considered for women with small rectovaginal fistulae with minimal fibrosis.}

Several case series demonstrated the limited but real utility of cautery for small vesicovaginal fistula that are not in proximity to the urethra or ureters..$^{22,23}$ Cautery may be carried out transvesically through a cystoscope, or vaginally, either as primary therapy or secondary treatment after surgical failure. Fistulae amenable to cautery are typically less that $0.7 \mathrm{~cm}$ in diameter. Catheter drainage for 2-3 weeks, with or without post-fulguration anticholinergic medications, is reported to close fistula.

Bioglue is a fibrin-based surgical adhesive composed bovine serum albumin mixed with glutaraldehyde. The albumin and glutaraldehyde induce a glue-like sealant in soft tissues. Used extensively in vascular surgical repair of the aorta, femoral and carotid arteries, it also has a documented utility in intestinovaginal fistulae..$^{24,25}$ The choice to use porcine plug, cautery and surgical glue mandates advanced fistula care experience. The use of any of these therapies must take place in an established fistula center, managed by an experienced fistula surgeon.

\section{Surgical management of fistula}

The first repair provides the optimal chance for successful closure in any given fistula patient.

\section{The basic principles of fistula surgery include:}

- Closure of the defect under no tension with wide mobilazation of bladder

- Avoid damage to upper urinary tract - stent ureters as needed

- Reinforce the bladder neck and anal sphincter when involved in the defect

- Adequate vascular supply - incorporation of flaps and grafts as needed

Dissection and suturing technique for fistula repair incorporates principles of plastic surgery. Most contemporary techniques avoid multiple layer closure in order to preserve bladder capacity.

\section{Wound healing optimization and biologic grafts for fistula surgery}

Traumatic wound and pelvic floor vaginal reconstructive surgery success rates have been demonstrated to benefit from the use of biosynthetic grafts. Though not currently popular in the obstetric fistula setting, some of these principles - debridement, high protein diet, adequate hydration, wound repair accelerating nutritional supplements, active management of diabetes, hypertension and chronic pulmonary disease, all warrant consideration in the pre and post-operative management of the genital fistula patient. In direct comparison to full thickness human skin (AlloDerm) and traditional woven Vicryl mesh, porcine submucosa (Surgisis) demonstrated superior collagen deposition and organization, and far superior neovascularization in an animal model study of abdominal hernia repair. ${ }^{26}$ Surgisis has demonstrated superior results in vaginal prolapse surgery, and has increasingly been used in the highly complicated 
rectovaginal fistula setting of Crohn's disease and obstetric rectoavaginal fistula. ${ }^{27,28}$ The possibility of incorporating porcine intestinal submucosal grafts warrants clinical trial in a high-prevalence obstetric fistula region.

\section{Wound healing optimization - potential frontiers}

The combination of stem cells and growth factors hasbeen shown to result in enhanced repair outcomes that emulated uninjured tissue. Preclinical evidence from gene therapy and stem cell studies are being used to move therapy from the experimental phase to clinical translation in other reconstructive surgical specialties..$^{29,30}$

\section{About flaps and grafts}

Flaps and interposition grafts are believed to improve blood flow to the fistula closure and may also be used to facilitate skin covering when the vaginal skin is inadequate. The use of flaps and grafts waxes and wanes, with the Martius graft, used to be popular and believed to reduce recurrence in past years. However, it is now falling from favor as experience shows the possibility of no clear added benefit. The labia minora, medial and/or lateral surface, and the labia majora, may be harvested in rotation flaps to cover the anterior, and less commonly, posterior vaginal wall, lending both blood flow and genital dermis covering to the fistula site. Perineal/perianal rotation skin flaps may be used to cover the posterior vaginal wall. Gracilis and wide buttock flaps are less commonly used, but have utility when healing by secondary intention is undesired, and no other suitable grafts are available. Peritoneum from the pouch of Douglas or vesicouterine reflection may also be accessed, and if adequate in surface area, advanced intravaginally to cover the anterior or posterior vaginal walls. Some fistula surgeons report success when open fistula repair beds are allowed to granulate spontaneously and where healing occurs by secondary intention. Meticulous nursing care and clinical monitoring is mandatory to the success of spontaneous epithelialization of an exposed fistula bed. ${ }^{2,31}$

\section{Principles of post-operation care}

The three D's of post-operative care are:

- Make sure that the client Drinks.

- Make sure that the client is Dry.

- Make sure that all drainages are Draining.

Intensive care is normally only for $12-24$ hours. The following morning the patients have to be mobilized like in any other operation; besides being good for their general health it is also good for prevention or treatment of contractures. Abundant fluid intake is needed for as long as there is a foley' scatheter inserted (usually a minimum period of 14 days) to prevent catheter blockage.

\section{Promoting wound healing}

A high protein diet, adequate hydration, and vitamin/ nutritional supplementation, designed to optimize wound healing, are advised. Menopausal and severely fibrotic patients may benefit from topical estrogen therapy.

\section{Using urinary tract drains}

Urinary catheters must be draining and patent at all times. A catheter blocked by kinking of tubing, or blood clot or mucus plug at the catheter tip in the bladder will quickly result in retention. Urinary retention can ruin a well-repaired fistula by bursting the suture line. If the bladder is full to palpation, any kinks in the tubing must be corrected immediately. If there are no kinks, or un-doing the kink does not produce efflux of urine, the catheter must be separated from the collection tubing. If this does not result in urine efflux, the catheter must be gently and immediately flushed with $20 \mathrm{ml}$ normal saline. If flushing with $\sim 20 \mathrm{ml}$ saline does not relieve the obstruction, the catheter may be changed. Stents may also kink, bend or be blocked by clots or mucus. Nondraining stents may be flushed with 3-5 $\mathrm{ml}$ saline. Duration of catheterization, traditionally 14 days, is undergoing scientific scrutiny, with preliminary results demonstrating safety and efficacy of flexible, case-by-case catheterization duration for as little as 7 days. ${ }^{32,33}$

\section{Bowel management}

Rectovaginal fistula patients must be in a state of very loose, soft stool so that stool does not distend the suture line in transit during a bowel movement.

\section{Expected activity}

Most surgeons leave the patient in bed for a day or two, ambulating carefully thereafter. Ankle rotations and gentle range - of - motion exercises may be instituted during the bed-rest phase, to maintain circulation and prevent deep vein thrombosis.

\section{Pre-discharge patient education}

Prior to discharge, the patient and her partner and family members, if present, should receive basic health and nutritional education to ensure that she maintains her overall general health. Further, she and her partner should receive full advice on family planning, contraception and the management of any subsequent pregnancies in an equipped hospital. 


\section{Re-integration}

Many patients are the poorests of poor and certainly appreciate financial help. However, in practice, if the patient is dry, she will re-integrate and, if she is wet, she may not. Those patients who are cured must be educated about the cause of their fistula and understand how fistulae should be prevented. They can then become educators for their own community.

\section{Special considerations}

\section{Urethral fistula and urethral reconstruction}

In urethral fistulae, the damaged urethral sphincter and the delicate architecture that creates particular challenges to the principle of adequate fistula mobilization require special attention. Transected urethra may be patent at the proximal end or blindended. When blind-ended, one may often restore patency with gentle pressure applied to the inserted metal catheter. With patency of the proximal urethral tube established, re-anastomosis to the bladder may involve postero-lateral compensatory reconstruction, or circumferential re-anastomosis to the robustly mobilized and advanced anterior and posterior/ trigonal bladder walls. ${ }^{2}$

\section{Recto-vaginalfistula (RVF)}

In obstructed labor, rectovaginal fistulae often accompany the more common vesicovaginal fistulae, often in a "cloacal" configuration with extensive vaginal fibrosis. If RVF occurs concomitant with urinary tract fistula, it may be advisable to close the RVF first. Then, followed by VVF closure after the $\mathrm{RVF}$ is healed, in order to reduce contaminant load and infection related failure of the VVF repair. The principles of RVF repair are the same as VVF repair, with the added problem of coliform contamination of the repair, and the possibility of constipated hard stool creating mechanical stressors on the repair suture line, warranting aggressive post-operation bowel management to keep stool soft. Care must be taken to screen for concomitant rectal stricture in the presence of RVF, and stricture revision may be done at time of RVF repair. Rectal wall flap may be rotated from the anterior rectum to create a neovaginal skin covering when vaginal and labial skin is not of adequate dimensions. Transverse closure of rectal defects reduces the possibility of repairrelated rectal stricture. When occurring in proximity to the rectal sphincter, it is sometimes best to transect the sphincter, repair the fistula and finish with sphincteroplasty. Perineoplasty and/or interposing levatorplasty may be used as needed to restore normal outlet anatomy, create an interposed layer between vagina and rectum, and to reduce suture line tension on the fistula and/or sphincter repairs.

\section{Abdominal repair of fistula}

The choice to proceed with abdominal repair dependson a combination of factors such as reimplantation of the ureter, the high fistula, difficulty to visualize and mobilize from below, leaking only per cervical os, the possibility indicating vesicouterine fistula and possibilites of more than one defect. ${ }^{34,35}$ The commonly cited "supratrigonal location" of VVF as an indication that abdominal access is inaccurate. Fistula located in the bladder dome, well above the level of the trigone, have been repaired vaginally by every experienced fistula surgeon. ${ }^{36}$ Vesicovaginal fistulae will be relatively low in the pelvis, mandating careful evaluation of the location of the ureteric orifices and liberal use of stents to increase ureteric safeguard throughout. Bladder stay-stitches are recommended to prevent the low bladder dissection from extending into the urethra. Vesicouterine fistulae require successful closure of the non-gravid uterine wall in addition to bladder closure. Dissection may be direct - circumferential around the defect, or by bladder-bivalve; incising vertically down to the bladder fistula, then circumscribing around its entirety, closing the bivalved bladder wall afterwards.

\section{Complicated fistula}

High rectovaginal, rectouterine/cervical or intestinovaginal/uterine fistulae mandate bowel preparation in advance of surgery. In addition, coliform/ anaerobic antibiotic coverage, careful adherence to the principles of intestinal dissection and suturing including adequate mobilization, avoiding intestinal devascularization, and transverse closure of intestinal lumens with Lambert suture technique are the mainstays. For high RVF, vaginal mobilization followed by abdominal closure may prove most efficacious. Colostomy for RVF is rarely necessary.

\section{Fistulae involving the ureter}

Fistulae involving the ureter and ureteric stenosis causing proximal hydro-ureter or hydronephrosis require ureteric re-implantation. Adequate mobilization is crucial to a tension-free reanastomosis of the ureter into the bladder. Once mobilization is complete, the ureter is transected at the lowest point, usually adjacent to the uterine artery. For ureters shortened by fibrosis, the anterior wall of the bladder may be tubularized on the lateral aspect to form a new distal ureter, and the anastomosis is made from this tubularized (Boari) flap to the short, proximal native ureter. 


\section{Fistulae that cannot be repaired}

Once an expert fistula surgeon, or two, has/have deemed the patient beyond the reach of normal pelvic reconstruction, the patient would be labeled incurable. Diversion methods include ileal conduit, continent ileal diversion, Mitrofanoff continent caecal diversion, and Mainz pouch diversions, where ureteric implantation into a detubularized sigmoid reroutes urine to stoma-free voiding per rectum. Reimplanted ureters may stricture and develop severe reflux. Intestinal lining may develop neoplastic tumors in response to exposure to urine. B12 deficiency requires constant monitoring in applicable diversion procedures, stones may form in the pouch, stomas, continent and incontinent, may stricture, prolapse, avulse, or develop soft tissue infection of the stoma itself or adjacent dermis., ${ }^{2,31}$ If the post-diversion conditions cannot be met, a diversion procedure is out of the question. For many women with fistula, fistulous efflux of bodily waste is preferred than a diverted stoma.

\section{Bladder and bowel dysfunctions after fistula surgery}

Dysfunctions of storage (incontinence) and emptying (voiding dysfunction all the way up to total urinary retention; defecatory dysfunction all the way up to fecal impaction or rectal obstruction) may occur individually or in combination after successful closure of a fistula defect. Incontinence is by definition symptomatic, but voiding and defecatory dysfunction may not be symptomatic, or may be symptomatic in atypical ways such that diagnosis can be difficult. For instance, some patients with overactive bladder may have post-void detrusor overactivity, where the bladder continues to contract even though it is empty. These patients often complain of incomplete emptying, when in fact they empty quite well, but the continued detrusor contraction makes them feel as if they still have more urine to void. A detailed history, careful physical examination and simple homework/office testing that help in accurate diagnosis are the key to successful treatment. Delineation of therapeutic success may be related to patient definition of success (closed, dry, coital capacity, fertile, pain-free, neurologically intact), surgically closed and continent, closed and somewhat incontinent, closed and severely incontinent, and closed with lower urinary or colorectal dysfunction other than incontinence.

\section{Persistent lower urinary tract dysfunction after fistula repair}

Up to $30 \%$ of patients suffer from urinary incontinence after repair of urinary tract fistula. ${ }^{34,35}$ The prevalence of post-fistula voiding dysfunction is not known, but is common to the experience of fistula clinicians. Urinary incontinence after obstetric fistula closure may be caused by:

- an overactive bladder,

- a poorly compliant- low capacity bladder,

- an atonic bladder with overflow incontinence,

- stress incontinence from urethral and/or direct sphincter damage,

- a combination of these conditions.

In its severest form, a totally non-functional urethral tube, called "drainpipe urethra", causes stress incontinence. Drainpipe urethra is common in full reconstruction of neo-urethra, as the urethra has no original fibro-sphincteric function or normal urinary tract alpha-adrenergic innervation of the bladder neck sphincter. There is a reconstructed bladder neck, but no nerves, and no sphincter. Loss of bladder wall surface area occurring with extensive fistulae typically results in severely reduced bladder capacity. Bladder fibrosis may lead to severe loss of bladder compliance. Rather than a 300-600 $\mathrm{ml}$ low-pressure urine reservoir, the bladder may have the volume capacity and elasticity of a walnut, requiring staged bladder augmentation or urinary diversion to reestablish the bladder's storage functions. Sling surgery will not help incontinence in this type of bladder. Any woman suffering from bladder storage (incontinence) or voiding phase (obstruction or impaired detrusor contractility) dysfunction after fistula repair warrants a meticulous consideration of all possible bladder conditions of storage and voiding.

\section{CONCLUSIONS}

National and International Organizations in developing countries like Nepal should effectively launch a campaign to end fistula, labeling this condition a preventable and treatable tragedy. The solution to the fistula problem will ultimately come from the provision of essential obstetric care service; however, the needs of those who have already developed fistula cannot be ignored therefore there is an enormous need for increasing the resources and skilled staff available locally to treat obstetric fistula to improve the lives of women currently living with this condition. Moreover, effective preventive strategies for obstetric fistula should be in place to reach those in need at the rural settings.

\section{REFERENCES}

1. Waaldijk K. Obstetric fistula surgery: art and science- the basics. Paris: WAHA International; 2010. 
2. Brian Hancock. Practical Obstetric Fistula Surgery. London: Royal Society of Medicine Press Ltd; 2009.

3. Ahmed S, Genadry R, Stanton C, Lalonde AB. Dead women walking: neglected millions with obstetric fistula. Int $\mathrm{J}$ Gyncol Obstet. 2007;99:S1-3.

4. Lewis $\mathrm{G}$, de Bernis L, eds. Obstetric fistula: guiding principles for clinical management and programme development. Geneva: World Health Organization; 2006.

5. UNFPA. Status of reproductive morbidities in Nepal. Kathmandu: UNFPA-Nepal; 2006.

6. Tebeu PM, Upadhyay M. Campaign to end fistula in Nepal: need assessment for obstetric fistula in Nepal. Kathmandu: UNFPA; 2011.

7. Stanton C, Holtz SA, Ahmed S. Challenges in measuring obstetric fistula. Int J Gynaecol Obstet. 2007;99:S4-S9.

8. World Health Organization Maternal Mortality Fact Sheet. Geneva: World Health Organization; 2012.

9. Onsrud M, Sjoveain S, Mukwege D. Cesarean deliveryrelated fistulae in the Democratic Republic of Congo. Int $\mathrm{J}$ Gynaecol Obstet. 2011;114(1):10-14.

10. Onsrud M, Sjoveian S, Luhiriri R, Mukwege D. Sexual violence-related fistulas in the Democratic Republic of Congo. Int J Gynaecol Obstet. 2008;103(3)265-9.

11. Head RB, Walker K, Secrest C. Large cystocele with spontaneous vesicovaginal fistula. Urology. 2012;80(3):e31. doi: 10.1016/j.urology.2012.05.020. [Epub 2012 Jul 26].

12. Wall LL, Arrowsmith SD, Briggs ND, Lassey A. Urinary incontinence in the developing world: the obstetric fistula. International Continence Society Committee 12.

13. Waaldijk K. Step by Step Surgery of Vesico-Vaginal Fistulas. Edinburgh: Campion Press; 1994.

14. Goh JWT, Krause HG. Female genital tract fistula. Brisbane: University of Queensland Press; 2004.

15. Tafesse B. New classification of female genital fistula. J Obstet Gynaecol Can. 2008;30(5):394-5.

16. Global Competency-based fistula surgery training manual. FIGO and Partners. London: FIGO; 2011.

17. Pregnancy, childbirth, postpartum and newborn care: a guide for essential practice. Geneva: World Health Organization; 2004.

18. Global action for skilled attendants for pregnant women. Geneva: World Health Organization; 2004.

19. Blaivas JG, Heritz DM, Romanzi LJ. Early versus late repair of vesicovaginal fistulas: vaginal and abdominal approaches. J Urol. 1995;153:1110.

20. Waaldijk K. The immediate management of fresh obstetric fistulas. Am J Obstet Gynecol. 2004;191(3):795-9.

21. Schwandner O, Euerst A. Preliminary results on efficacy in closure of transphincteric and rectovaginal fistulas associated with Crohn's disease using new biomaterials. Surg Innov. 2009;16(2):162-8.

22. Stovsky MD, Ignatoff JM, Blum MD, Nanninga JB, O'Conor VJ, Kursh ED. Use of electrocoagulation in the treatment of vesicovaginal fistulas. J Urol. 1994;152:1443-4.

23. Shah SJ. Role of day care vesicovaginal fistula fulguration in small vesicovaginal fistula. J Endourol. 2010;24(10):165960 .

24. de la Portilla F, Rada R, Vega J, Cisneros N, Maldonado VH, Sanchez-Gil JM. Long-term results change conclusions on BioGlue in the treatment of high transsphinteric anal fistulas. Dis Colon Rectum. 2010;53:1220-1.

25. Garcia S, Dissanaike S. Case report: treatment of rectovaginal fistula with Bioglue ${ }^{\circledR}$. Int J Surg Case Rep. 2012;3(7):327-9.

26. Rice RD, Ayubi FS, Shaub ZJ, Parker DM, Armstrong PJ, Tsai JW. Comparison of Surgisis, AlloDerm and Vicryl Woven Mesh grafts for abdominal wall defect repair in an animal model. Aesthetic Plast Surg. 2010;34(3):290.

27. Armitage S, Seman EI, Keirse MJ. Use of surgisis for treatment of anterior and posterior vaginal prolapse. Obstet Gynecol Int. 2012; 376251.[Epub 2012 Jan 15].

28. Schwandner O, Fuerst A, Kunstreich $\mathrm{K}$, Scherer $\mathrm{R}$. Innovative technique for the closure of rectovaginal fistula using Surgisis mesh. Tech Coloproctol. 2009;13(2):135-40.

29. Isaac C, Gharaibeh B, Witt M. Wright VJ, Huard J. Biologic approaches to enhance rotator cuff healing after injury. J Shoulder Elbow Surg. 2012;21(2):181-90.

30. Nixon AJ, Watts AE, Schnabel LV. Cell-and gene-based approaches to tendon regeneration. J Shoulder Elbow Surg. 2012;21(2):278-94

31. Atlas of Pelvic Surgery. Clifford Wheeless and Marcella Roenneberg. [cited 2013 March 7]. Available from http:// www.atlasofpelvicsurgery.com

32. Barone MA, Frajzyngier V, Arrowsmith S, Ruminjo J, Seuc A, Landry E, et al. Non-inferiority of short-term urethral catheterization following fistula repair surgery: study protocol for a randomized-controlled trial. BMC Womens Health. 2012;12:5.

33. Nardos R, Menber B, Browning A. Outcome of obstetric fistula repair after 10 day versus 14-day Foley catheterization. Int J Gynaecol Obstet. 2012;118(1):21-3.

34. Creanga AA, Genadry RR. Obstetric fistulas: a clinical review. Int J Gynaecol Obstet. 2007;99(Suppl)1:S40-6.

35. Arrowsmith SD, Ruminjo J, Landry EG. Current practices in treatment of female genital fistula: a cross sectional study. BMC Pregnancy and Childbirth. 2010;10:73.

36. Frajzyngier V, Ruminjo J, Asiimwe F, Barry T, Bello A, Danladi D, et al. Factors influencing choice of surgical route of repair of genitourinary fistula, and the influence of route of repair on surgical outcomes: findings from a prospective cohort study. BJOG. 2012. doi: 10.1111/j.14710528.2012.03461.x. [Epub ahead of print]. 